\title{
Application of HEC-HMS for Flood Forecasting in Kabkian Basin and Delibajak Subbasin in Iran
}

\author{
Arash Asadi, Fardin Boostani \\ Islamic Azad University Dehdasht branch, Iran \\ Assistant professor, Science and Research Branch, Islamic Azad University, Fars, Iran
}

\begin{abstract}
Rainfall-runoff processes in small subbasin Delibajak $\left(16.3 \mathrm{~km}^{2}\right)$ and Kabkian basin $\left(846.5 \mathrm{~km}^{2}\right)$ in kohgilouye and boyerahmad, iran were examined. in fact, Delibajak is one of the subbasins of Kabkian basin. In this study, basins divided into a number of sub- basins where the hydrologic parameters may vary from one sub-basin to another. In such case, lumped models may be labeled as "semi-distributed."The hydrologic model HEC-HMS (Hydrologic Engineering Center, Hydrologic Modeling System), used in combination with the Geospatial Hydrologic Modeling Extension, HEC-GeoHMS. The SCS curve number method (Soil conservation Service, 1972) was considered for the Rainfall-runoff modelling and The model was carefully calibrated and verified in subbasin and basin using simultaneous historical observed data. The determination coefficients and coefficients of agreement for all the flood events were above 0.9 , and the percent errors in peak flow and volume were all within the acceptable range. As well, the hydrologic parameters, curve number and initial abstraction were compared in this two basin. In the Kabkian basin, curve number and initial abstraction, ranges from 61 to 66 , and $33 \mathrm{~mm}$ to $40 \mathrm{~mm}$, respectively. In the Delibajak subbasin, this parameteres ranges from 51 to 53 , and 47 $\mathrm{mm}$ to $51 \mathrm{~mm}$. This variationes is due to differences in slope, geologic formations, vegetation cover and land use in subbasins.
\end{abstract}

Keywords: - Delibajak subbasin, Kabkian basin, HEC-HMS, hydrologic modelling, Rainfall-runoff modelling, HEC-GeoHMS,SCS, kohgilouye and boyerahmad.

\section{INTRODUCTION}

Currently available watershed models range from simple conceptual lumped models to comprehensive physically based distributed models. Conceptual lumped models use an integrated description of parameters representing an average value over the entire basin. A watershed can be divided into a number of sub- basins where the hydrologic parameters may vary from one sub-basin to another. In such case, lumped models may be labeled as "semi-distributed." They remain non-physically based, however, as they use synthetic methods of transforming rainfall to runoff. This study used the HEC-HMS Version 3.2. The HEC model is designed to simulate the surface runoff response of a basin to precipitation by representing the basin with interconnected hydrologic and hydraulic components. It is primarily applicable to flood simulations. In HEC-HMS, the basin model comprises three vital processes; the loss, the transform and the base flow. Each element in the model performs different functions of the precipitation-runoff process within a portion of the basin or basin known as a sub-basin. An element may depict a surface runoff, a stream channel, or a reservoir. Each of the elements is assigned a variable which defines the particular attribute of the element and mathematical relations that describe its physical processes. The result of the modeling process is the computation of stream flow hydrographs at the basin outlet. The design, construction and operation of many hydraulic projects require an adequate knowledge of the variation of the basin's runoff, and for most of these problems it would be ideal to know the exact magnitude and the actual time of occurrence of all stream flow events during the construction period and economic life of the project. If this information was available at the project planning and design stages, it would be possible to select from amongst all alternatives a design, construction program, and operational procedure that would produce a project output with an optimized objective function. Unfortunately, such ideal and precise information is never available because it is impossible to have advance knowledge of the project hydrology for water resources development projects; it is necessary to develop plans, designs, and management techniques using a hypothetical set of future hydrologic conditions. It is the determination of these future hydrologic conditions that has long occupied the attention of engineering hydrologists who have attempted to identify acceptable simplifications of complex hydrologic phenomena and to develop adequate models for the prediction of the responses of basins to various natural and anthropogenic hydrologic and hydraulic phenomena. In view of these, a number of hydrologic models have been developed for flood forecasting and the study of rainfall-runoff processes (Yusop and Chan, 2007; Yener and orman,2008; Li and Jia, 2008; Stisen and Jensen,2008; Khakbaz and et al,2009; Salerno and Tartari, 2009; Amir and Emad,2010; Jang and Kim, 2010; James and Zhi,2010;). In recent times, GIS (geographic information systems) has become an integral part of hydrologic studies because of 
the spatial character of the parameters and precipitation controlling hydrologic processes. GIS plays a major role in distributed hydrologic model parameterization. This is to overcome gross simplifications made through representation by lumping of parameters at the river basin scale. The extraction of hydrologic information, such as flow direction, flow accumulation, watershed boundaries, and stream networks, from a DEM (digital elevation model) is accomplished through GIS applications. This study combined GIS with HEC-HMS, and analyzed the model's suitability for the studied basins. Kabkian basin and Delibajak subbasin are selected as the study areas in this research and basin parameters(curve number and initial abstraction) are calibrated using the rainfall-runoff data of the basin that are collected by 12 rainfall and 2 runoff stations for 2009-2011 period.

The present study has two main objectives: (1) calibration and verification of the HEC-HMS hydrologic model in Kabkian basin and Delibajak subbasin, and (2) The comparison between hydrologic parameters(curve number and initial abstraction) in basins.

\section{The Study Area}

\section{MATERIALS AND METHODS}

The model was applied to two basins: the Delibajak and Kabkian basin. The basins are located in the west of Yasooj City,kohgilouye and boyerahmad Province in Southwest iran. The Kabkian Basin is in between $30^{\circ} 26^{\prime}-30^{\circ} 54^{\prime}$ northern latitudes and $51^{\circ} 05^{\prime}-51^{\circ} 37^{\prime}$ eastern longitudes. This basin is one of the subbasins of Karoon river. The watershed has a total basin area of $846.5 \mathrm{~km}^{2}$ with an elevation ranging from 1500 to $3000 \mathrm{~m}$.Average annual precipitation is about $973 \mathrm{~mm}$ of which over $90 \%$ occurs between November to April in the form of frontal rainfall induced flood. The Delibajak subbasin is located in the SouthEast part of Kabkian Basin, has a total area of $16.3 \mathrm{~km}^{2}$ with an elevation ranging from 2100 to $2750 \mathrm{~m}$. (Fig 1.)

\section{Data used}

In the kabkian basin ,streamflow and precipitation have been monitored since 2000 by the kogilouye and boyerahmad Regional Water Authority.As well, in Delibajak subbasin this data have been monitored since 2010 by the gricultural research center.Precipitation data was collected by 12 raingauges located in the middle and lower parts of the basin.Stream flow data were collected at the outlets of the basins (Delibajak and botari hydrometric stations) at one hour interval. meteorological data were acquired from the local climatological station. All the hydrologic model simulations are performed on an hourly time step basis.

\section{Hec-GeoHMS 5.0}

\section{SOFTWARE USED}

It is a geospatial hydrology toolkit for engineers with limited GIS experience[USACE-HEC, 2003]. It is an extension package used in ArcMap software. In this study, Hec-GeoHMS is used to derive river network of the basins and to delineate subbasins of the basins from the digital elevation model (DEM) of the basins. In the subbasins delineation process streamflow gages botari and Delibajak are used for Kabkian and Delibajak basin,respectively.

\section{HEC-HMS 3.2}

It is a hydrologic modeling software developed by US Army Corps of Engineers Hydrologic Engineering Center. It includes many of the well-known and well applicable hydrologic methods to be used to simulate rainfall-runoff processes in river basins. [USACE-HEC, 2006].

\section{MODEL APPLICATION AND CALIBRATION}

In this study, 3 flood events that occurred during the three-year period of 2009-2011 in the Kabkian Basin and Delibajak subbasin were used for model testing,simultaneously. An HEC- HMS project must have the following components before it can be run: a basin model, a meteorological model, and control specifications. The basin model and basin features were created in the form of a background map file imported to HMS from the data derived through HEC-GeoHMS for model simulation (Fig. 2 and Fig. 3). The observed precipitation and discharge data were used to create the meteorological model using the user gauge weighting method and, subsequently, the control specification model was created. The control specifications determine the time pattern for the simulation; its features are: a starting date and time, an ending date and time, and a computation time step. To run the system, the basin model, the meteorological model, and the control specifications were combined. The observed historical data of twelve raingauge stations representing each subbasin and one stream gauge station in the Kabkian Basin, and one recording raingauge stations and one stream gauge station in the Delibajak subbasin, were used for model calibration and verification. An hourly time step was used for the simulation based on the time interval of the available observed data. 
The SCS curve number method was employed to model infiltration loss. The SCS (Soil Conservation Service) unit hydrograph method was used to model the transformation of precipitation excess into direct surface runoff. The constant monthly method was employed to model baseflow. The Muskingum routing model was used to model the reaches.

Each method in HEC-HMS has parameters and the values of these parameters should be entered as input to the model to obtain the simulated runoff hydrographs. Some of the parameters may be estimated by observation and measurements of stream and basin characteristics, but some of them cannot be estimated. When the required parameters can not be estimated accurately, the model parameters are calibrated, i.e. in the presence of rainfall and runoff data the optimum parameters are found as a result of a systematic search process that yield the best fit between the observed runoff and the computed runoff. This systematic search process is called as optimization. Optimization begins from initial parameter estimates and adjusts them so that the simulated results match the observed streamflow as closely as possible.

The trial and error method, in which the hydrologist makes a subjective adjustment of parameter values in between simulations in order to arrive at the minimum values of parameters that give the best fit between the observed and simulated hydrograph, was employed to calibrate the model. Although the model was calibrated manually, the HEC-HMS built-in automatic optimization procedure was used to authenticate the acceptability and suitability of the parameter values and their ranges as applicable to their uses in HEC-HMS. The choice of the objective function depends upon the need. The SCS curve number method, which is used to handle the infiltration loss in the subbasins, has three parameters such as: curve number, initial abstraction and percent impervious area in the basin. Percent impervious area is taken as " $0 \%$ ", since no urban settlements were present inside the subbasin. Therefore, the remaining two parameters (curve number, initial abstraction ) of SCS curve number method are calibrated. The SCS unit hydrograph method, which is used to model the transformation of precipitation excess into direct surface runoff, has lag time parameters. This parameter was calibrated,as well.

\section{MODEL PERFORMANCE EVALUATION METHODS}

The criteria used to evaluate the performance of the models are the overall agreement between predicted and measured runoff discharges, and the models' ability to predict time and magnitude of hydrograph peaks, and runoff volume. The following statistical measures were used to quantify the performance accuracy of both models during each simulation periods, and combined over all periods:

- $\quad$ Percent error in peak flow $(P E P F)$. The PEPF measure only considers the magnitude of computed peak flow and does not account for total volume or timing of the peak:

$$
P E P F=100\left|\frac{Q_{0}(\text { peak })-Q_{S}(\text { peak })}{Q_{Q}(\text { peak })}\right|
$$

where $Q_{O}\left(Q_{S}\right)$ is the the observed (simulated) flow.

- $\quad$ Percent error in volume $(P E V)$. The $P E V$ function only considers the computed volume and does not account for the magnitude or timing of the peak flow:

$$
P E V=100\left|\frac{V_{O}-V_{S}}{V_{O}}\right|
$$

where $V_{O}\left(V_{S}\right)$ is the volume of the observed (simulated) hydrograph.

- Coefficient of correlation $(R)$. The lag- 0 cross correlation coefficient was calculated as:

$$
R=\frac{\sum_{t=1}^{N}\left(O_{t}-\bar{O}\right) \times\left(S_{t}-\bar{S}\right)}{\sqrt{\left[\sum_{t=1}^{N}\left(O_{t}-\bar{O}\right)^{2} \times \sum_{t=1}^{N}\left(S_{t}-\bar{S}\right)^{2}\right]}}
$$

Where $O_{t}\left(S_{t}\right)$ is the observed (simulated) flow at time $t$, and $\bar{O}(\bar{S})$ is the average observed (simulated) flow during the calibration period.

- The relative root mean squared error, RRMSE, were calculated as:

$$
R R M S E=100 \times \sqrt{\frac{1}{N} \sum_{t=1}^{N}\left(\frac{S_{t}-O_{t}}{O_{t}}\right)^{2}}
$$

where $N$ is the number of streamflow ordinates and the meaning of the remaining symbols is the same as in Equation (3). 


\section{RESULTS AND DISCUSSION}

As described in the introduction, each component of HEC-HMS models an aspect of the precipitationrunoff process within a portion of the basin, commonly referred to as a sub-basin. Representation of a component requires a set of parameters that specify the particular characteristics of the component and mathematical relations that describe the physical processes. Tables 1 and 2 below show the calibrated parameter values of each of the components represented in this model. Apart from the sub-areas, which are fixed, parameters were calibrated simultaneously through adjustment of their values until a good agreement between the observed and simulated hydrographs was achieved.

The calibration and validation graphs of the two basins are shown below. Figs. 4 through 9 show good agreement between observed and simulated graphs. Also, Tables 3 and 4 show observed and simulated values for both calibration and validation of the two basins. Table 5 show a summary of the models performance. It can be seen in the above graphs that the simulated and observed peak discharges occurred on the same day, and their maximum time difference was one hour, which is acceptable for flood forecasting.

\section{CONCLUSIONS}

As shown in the results above, the model predicted peak discharge accurately based on the available historical flood data. Both the flood volume and timing were fairly accurate. This shows that HEC-HMS is suitable for the studied basins. In the Kabkian basin, The hydrologic parameters, curve number and initial abstraction, ranges from 61 to 66 , and $33 \mathrm{~mm}$ to $40 \mathrm{~mm}$, respectively.In the Delibajak subbasin, this parameteres ranges from 51 to 53 , and $47 \mathrm{~mm}$ to $51 \mathrm{~mm}$. This variationes is due to differences in slope, geologic formations, vegetation cover and land use in subbasins.From the results, we can conclude that the complexity of the model structure does not determine its suitability and efficiency. Though the structure of HEC-HMS is simple, it is a powerful tool for flood forecasting. A further application of HEC-HMS should be encouraged to confirm its suitability for the iran basins.

\section{REFERENCES}

[1] Amir. A, Emad. H,2010,Application of a Conceptual Hydrologic Model in Teaching Hydrologic Processes, Int. J. Engng Ed. Vol. 26, No. 4, pp. 1-11, 2010

[2] James .O,Zhi-j. L ,2010,Application of HEC-HMS for flood forecasting in Misai and Wan'an catchments in China, Water Science and Engineering, 2010, 3(1): 14-22

[3] Jang, T. I. and Kim, H. K., 2010.Estimation of storm hydrographs in a mixed - land use watershed using a modified TR-20 model.

[4] Khakbaz, B., et al,2009. From lumped to distributed via semi-distributed: Calibration strategies for semidistributed hydrologic models. J. Hydrol. doi:10.1016

[5] 5-Li, S. Y., Qi, R. Z., and Jia, W. W. 2008. Calibration of the conceptual rainfall-runoff model's parameters. Proceeding of 16th IAHR-APD Congress and 3rd Symposium of IAHR-ISHS, 55-59. Beijing: Tsinghua University Press.

[6] 6-Parajka J,Blosch G,2010,The value of MODIS snow cover data in Validating and calibrating conceptual hydrologic model, Journal of Hydrology, vol 358,240-258.

[7] 7- Salerno, F., and Tartari, G., 2009, "A coupled approach of surface hydrological modelling and Wavelet Analysis for understanding the baseflow components of river discharge in karst environments", Journal of Hydrology, Volume 376, Issues 1-2, Pages 295-306.

[8] 8- Stisen.S,Jensen.K,2008, A Remote Sensing driven distributed hydrological model of the Senegal river basin,journal of hydrology 354:131-148.

[9] 9-U. S. Army Corps of Engineers (USACE), 2009b, Hydrologic Modeling System: Technical Reference Manual, Davis, CA: U.S. Army Corps of Engineers, Hydrologic Engineering Center.

[10] 10-U. S. Army Corps of Engineers (USACE), 2000a,Geospatial modeling extension. HEC-GeoHMS, User's Manual, Davis, CA: U.S. Army Corps of Engineers, Hydrologic Engineering Center.

[11] 11- Yener, M.K. orman, A.Ü.2008. Modeling Studies With Hec-Hms and Runoff Scenariosin Yuvacik Basin, Turkiye. Department of Civil Engineering, Middle East Technical University, 06531 Ankara/Türkiye.

[12] 12- Z. Yusop, C.H. Chan and A, 2007,Katimon,Runoff characteristics and application of HEC-HMS for modelling stormflow hydrograph in an oil palm catchment, Water Science \& Technology Vol 56 No 8 pp $41-48$ 

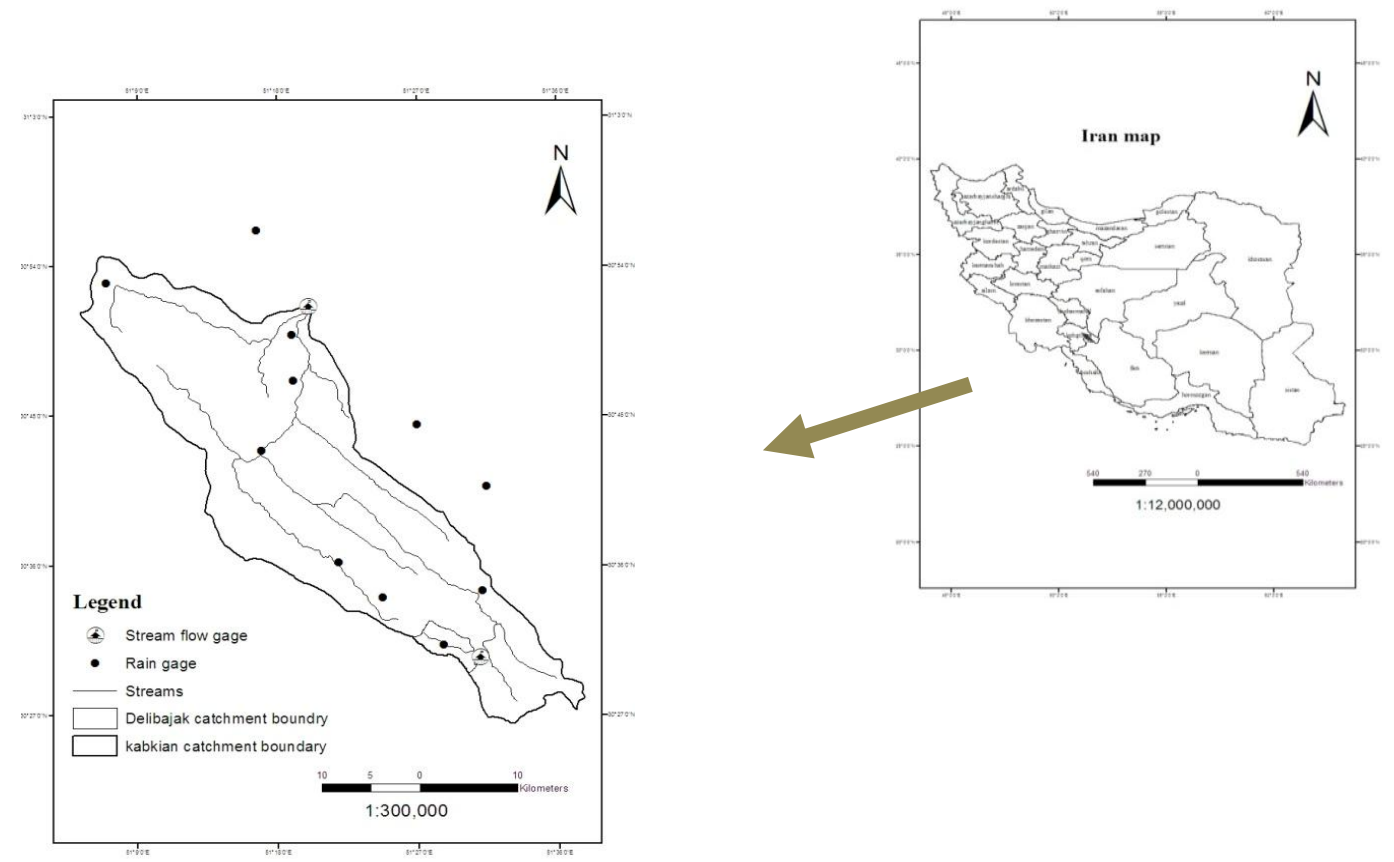

Fig 1. Regional map of Iran, location of study basins and monitoring stations.

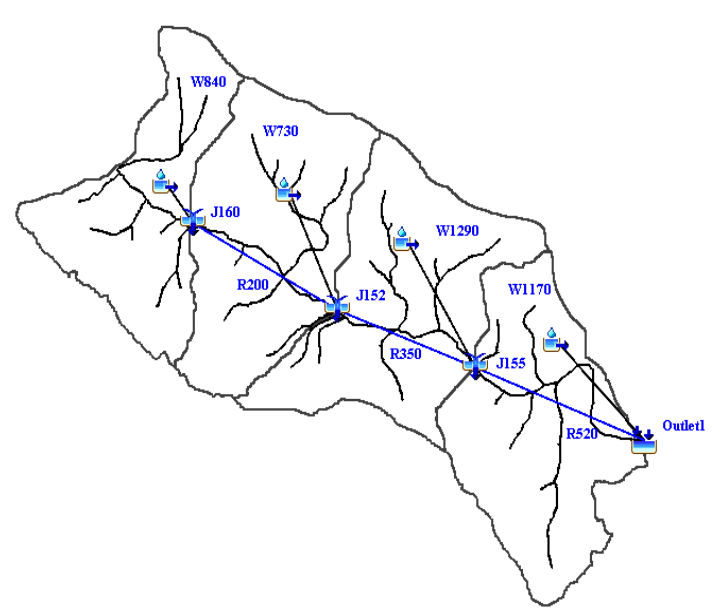

Fig 2. Processed results for Kabkian basin imported to HEC- HMS for simulation.

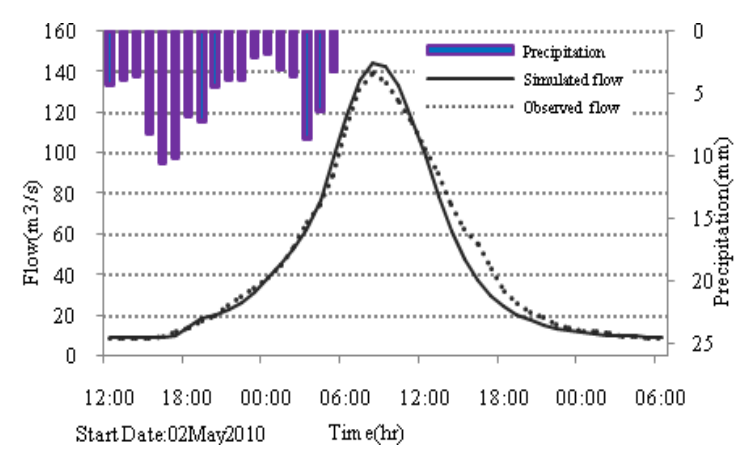

Fig 4. Observed vs. simulated flow in May 2010 for Kabkian basin calibration

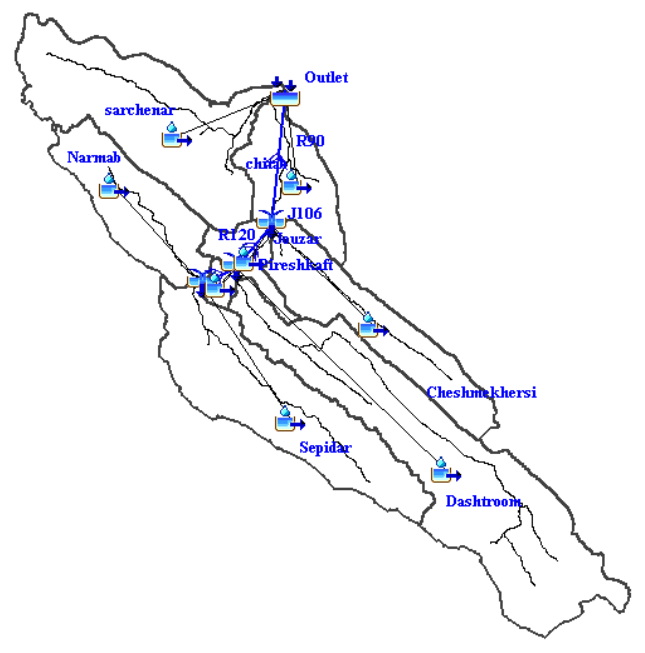

Fig 3. Processed results for Delibajak basin imported to HEC- HMS for simulation

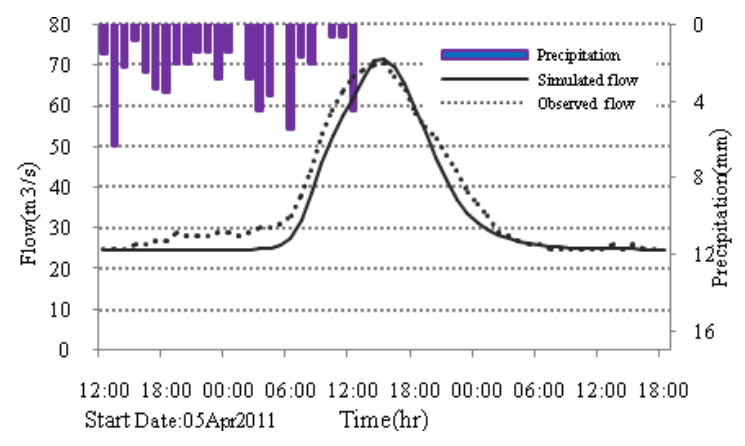

Fig 5. Observed vs. simulated flow in Apr 2011 for Kabkian basin validation 


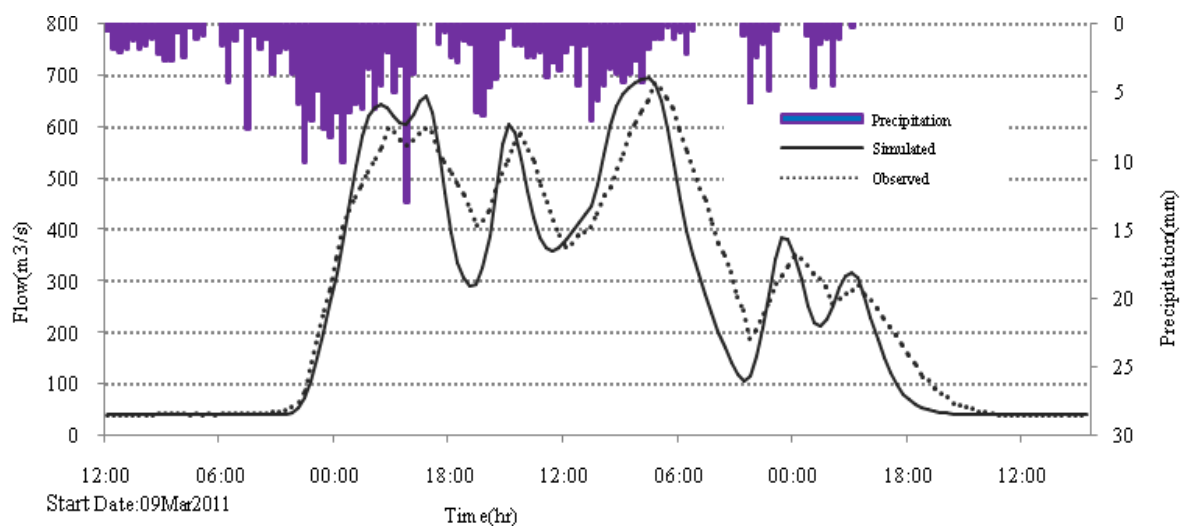

Fig 6. Observed vs. simulated flow in Mar 2011 for Kabkian basin calibration

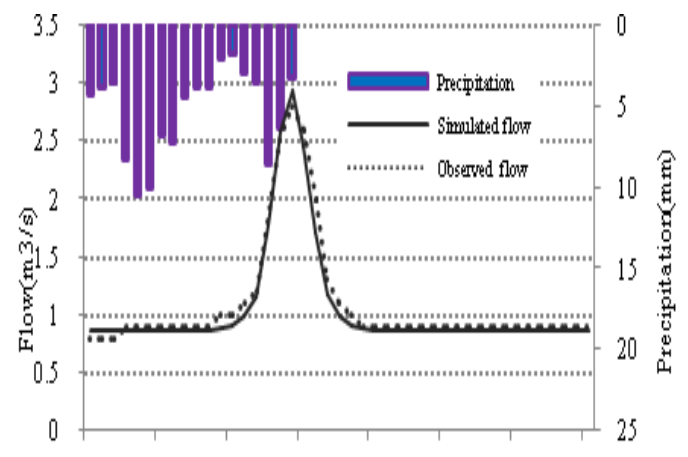

$\begin{array}{llllllll}12: 00 & 18: 00 & 00: 00 & 06: 00 & 12: 00 & 18: 00 & 00: 00 & 06: 00\end{array}$ StartDate:02May2010 Time(hr)

Fig 8. Observed vs. simulated flow in May 2010

for Delibajak basin calibration

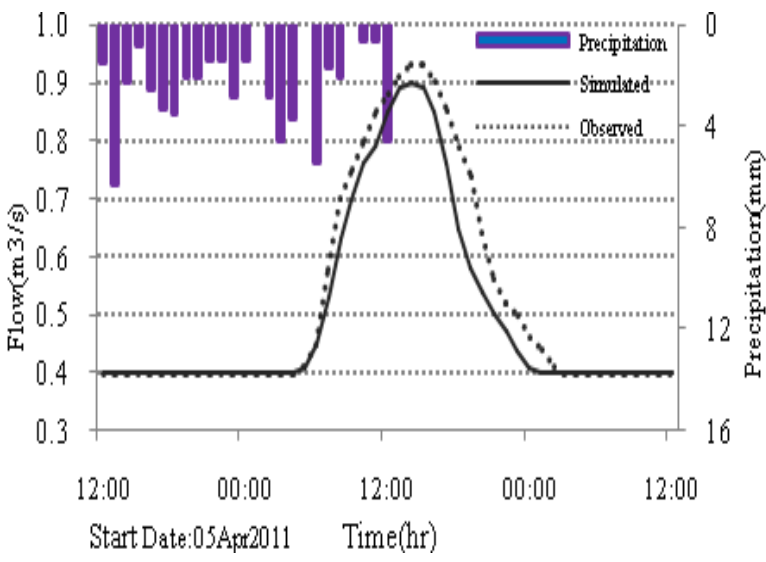

Fig 7. Observed vs. simulated flow in Apr 2011 for Delibajak basin validation

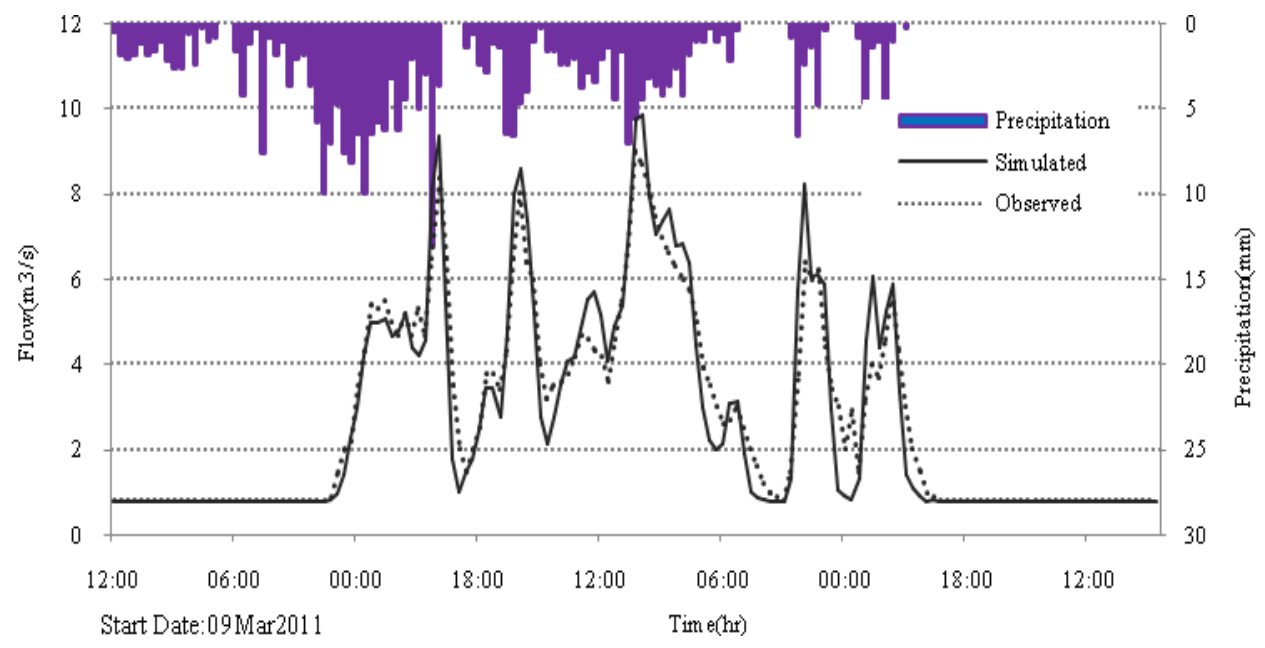

Fig 9. Observed vs. simulated flow in Mar 2011 for Delibajak basin calibration 
Table 1. Calibrated parameter values of Kabkian Basin

\begin{tabular}{ccccccc}
\hline \multirow{2}{*}{ Sub-basin } & Area $\left(\mathrm{km}^{2}\right)$ & $\begin{array}{c}\text { Curve } \\
\text { Number }\end{array}$ & $\begin{array}{c}\text { Initial } \\
(\mathrm{CN})\end{array}$ & $\begin{array}{c}\text { Abstraction } \\
(\mathrm{mm})\end{array}$ & $\begin{array}{c}\text { SCS Lag } \\
(\mathrm{min})\end{array}$ & \multicolumn{2}{c}{ Muskingum coefficient } \\
\hline Sarchenar & 171.4 & 62.6 & 35.2 & 279.2 & $X$ & $K(\mathrm{hr})$ \\
Chitab & 66.0 & 61.5 & 54.2 & 80.6 & .2 & - \\
Narmab & 82.1 & 61.5 & 36.4 & 114.6 & - & - \\
Jouzar & 25.3 & 61.5 & 22.8 & 26.2 & .2 & .48 \\
Pireshkaft & 8.4 & 67.0 & 21.6 & 20.5 & .2 & .53 \\
Cheshmekhersi & 93.4 & 61.7 & 35.2 & 150.0 & - & - \\
Dashtroom & 247.3 & 61.2 & 39.0 & 294.9 & - & - \\
Sepidar & 152.6 & 60.8 & 41.1 & 293.5 & - & - \\
\hline
\end{tabular}

Table 2. Calibrated parameter values of Delibajak Basin

\begin{tabular}{ccccccc}
\hline Sub-basin & Area $\left(\mathrm{km}^{2}\right)$ & $\begin{array}{c}\text { Curve } \\
\text { Number } \\
\text { (CN) }\end{array}$ & $\begin{array}{c}\text { Abstraction } \\
(\mathrm{mm})\end{array}$ & $\begin{array}{c}\text { SCS Lag } \\
(\text { min })\end{array}$ & \multicolumn{2}{c}{ Muskingum coefficient } \\
\hline W840 & 4.3 & 51.1 & 47.2 & 42.2 & - & $K(\mathrm{hr})$ \\
W730 & 4.4 & 51.7 & 50.5 & 84.3 & .2 & .28 \\
W1290 & 4.3 & 52.5 & 48.6 & 49.9 & .2 & .25 \\
W1170 & 3.3 & 51.5 & 47.1 & 78.1 & .2 & .39 \\
\hline
\end{tabular}

Table 3. Calibration and validation results for Kabkian Basin

\begin{tabular}{|c|c|c|c|c|c|c|c|}
\hline \multirow{2}{*}{ Period } & \multirow{2}{*}{ Date } & \multicolumn{3}{|c|}{ Simulated } & \multicolumn{3}{|c|}{ Observed } \\
\hline & & $Q_{s}\left(m^{3} / s\right)$ & $V_{s}\left(1000 \mathrm{~m}^{3}\right)$ & Time to peak & $Q_{s}\left(m^{3} / s\right)$ & $V_{s}\left(1000 m^{3}\right)$ & Time to peak \\
\hline \multirow{2}{*}{$\begin{array}{c}\text { Calibrati } \\
\text { on }\end{array}$} & $\begin{array}{c}\text { 02May } 20 \\
10\end{array}$ & 144.2 & 6779.3 & $\begin{array}{c}\text { 03May } 2010,08: \\
00\end{array}$ & 140 & 7030.8 & $\begin{array}{c}\text { 03May } 2010,08: \\
00\end{array}$ \\
\hline & $\begin{array}{c}\text { 09Mar } 201 \\
1 \\
\end{array}$ & 696 & 14062.7 & $\begin{array}{c}13 \mathrm{Mar} 2011,01: \\
00\end{array}$ & 684 & 154809 & $\begin{array}{c}13 \mathrm{Mar} 2011,02: \\
00\end{array}$ \\
\hline $\begin{array}{c}\text { Validatio } \\
\text { n }\end{array}$ & $\begin{array}{c}\text { 05Apr201 } \\
1\end{array}$ & 71.4 & 6659.5 & $\begin{array}{c}\text { 06Apr2011,15: } \\
00\end{array}$ & 70.5 & 7116.6 & $\begin{array}{c}\text { 06Apr2011,15: } \\
00\end{array}$ \\
\hline
\end{tabular}

Table 4. Calibration and validation results for Delibajak sub-basin

\begin{tabular}{|c|c|c|c|c|c|c|c|}
\hline \multirow{2}{*}{ Period } & \multirow{2}{*}{ Date } & \multicolumn{3}{|c|}{ Simulated } & \multicolumn{3}{|c|}{ Observed } \\
\hline & & $Q_{s}\left(\mathrm{~m}^{3} / \mathrm{s}\right.$ & $V_{s}\left(1000 \mathrm{~m}^{3}\right)$ & Time to peak & $Q_{s}\left(m^{3} / s\right)$ & $V_{s}\left(1000 \mathrm{~m}^{3}\right)$ & Time to peak \\
\hline \multirow{2}{*}{$\begin{array}{l}\text { Calibrati } \\
\text { on }\end{array}$} & $\begin{array}{c}\text { 02May } 20 \\
10\end{array}$ & 2.9 & 159.4 & $\begin{array}{c}\text { 03May2010,05: } \\
00\end{array}$ & 2.8 & 166.1 & $\begin{array}{c}\text { 03May2 } 010,05: \\
00\end{array}$ \\
\hline & $\begin{array}{c}09 \mathrm{Mar} 201 \\
1\end{array}$ & 9.8 & 1494.5 & $\begin{array}{c}12 \mathrm{Mar} 2011,18: \\
00\end{array}$ & 9 & 1515 & $\begin{array}{c}\text { 12Mar2011,17: } \\
00\end{array}$ \\
\hline $\begin{array}{c}\text { Validatio } \\
\text { n }\end{array}$ & $\begin{array}{c}05 \mathrm{Apr} 201 \\
1\end{array}$ & .9 & 95.8 & $\begin{array}{c}\text { 06Apr2011,14: } \\
00\end{array}$ & .93 & 100.1 & $\begin{array}{l}\text { 06Apr2011,14: } \\
00\end{array}$ \\
\hline
\end{tabular}

Table 5. Model performance evaluation for selected storm events

\begin{tabular}{|c|c|c|c|c|c|c|}
\hline \multirow{2}{*}{ Basin } & \multirow{2}{*}{ Period } & \multirow{2}{*}{ Date } & \multicolumn{4}{|c|}{ Evaluation criteria } \\
\hline & & & $\operatorname{PEPF}(\%)$ & $\mathrm{PEV}(\%)$ & $\mathrm{R}$ & RRMSE $(\%)$ \\
\hline \multirow{3}{*}{ Kabkian } & \multirow{2}{*}{ Calibration } & $02 \mathrm{May} 2010$ & .6 & 6.8 & .99 & 12 \\
\hline & & $09 \mathrm{Mar} 2011$ & 1.8 & 6.9 & .97 & 21.9 \\
\hline & Validation & 05Apr2011 & 1.3 & 6.4 & .99 & 9.2 \\
\hline \multirow{3}{*}{ Delibajak } & \multirow[t]{2}{*}{ Calibration } & $02 \mathrm{May} 2010$ & 8.8 & 1.4 & .99 & 6.1 \\
\hline & & $09 \mathrm{Mar} 2011$ & 6.6 & 1.6 & .98 & 12.7 \\
\hline & Validation & $05 \mathrm{Apr} 2011$ & 3.2 & 4.3 & .98 & 6.5 \\
\hline
\end{tabular}

